\title{
Ovarian Dermoid Cyst with Adenocarcinoma
}

National Cancer Institute

\section{Source}

National Cancer Institute. Ovarian Dermoid Cyst with Adenocarcinoma. NCI Thesaurus.

Code C39999.

A secondary adenocarcinoma that has developed in an ovarian dermoid cyst. 